\title{
Impact of Management Practices on Micro and Small Enterprise (MSEs) Performance in Marinduque, Philippines
}

\author{
Michael V. Capiña \\ School of Business \& Management, Marinduque State College, Philippines
}

\begin{abstract}
In the Philippines, micro and small enterprises (MSEs) comprise the largest part of the business economic undertakings and are among the most important development agents in rural communities like Marinduque. MSEs offer opportunities to poor people the possibility of earning income, training, work experience and employment. However, most of the micro and small enterprises in the country perform behind the neighboring ASEAN countries. Thus, assessing the impact of their management practices on operational functions (marketing, production, financial, human resources) and the significant relationship to MSEs performance (sales, production, and income) as the basis for government interventions. The study disclosed that management practices of 35 selected manufacturing MSEs on operational function is doing well with an overall mean of 3.70 interpreted as "Mostly Practiced". Of all the variables, marketing emerged to have the highest mean of 3.95, interpreted as "Mostly Practiced". What is alarming is the findings on human resources, which got the lowest mean of 3.40, interpreted as "Practiced". Overall performance in terms of sales, production, and income is 3.64 , interpreted as "very satisfactory". Using Pearson, the operational business function has a positive correlation to performance. Based on the operational management practices, the following have a vital role for the success of MSEs such as type of business organization, decision-making process, creation of policy, rules, and regulations, planning and implementation, and management directions of the enterprise. As to these findings, programs of government will need to give emphasis on the weak areas and highlight the good practices as a basis for crafting tailored interventions for each MSEs.
\end{abstract}

Keywords: Development agent; rural community; human resources; Micro and Small Enterprise (MSEs); operational functions

This is an open access article under the CC-BY-NC license.

\section{INTRODUCTION}

The vital contribution of a vigorous and healthy micro, small and medium-sized enterprise (MSMEs) sector to the national economy and social progress of countries across the world has been widely recognized. In a developing economy like the Philippines, MSMEs play a critical role. In 2017, the MSMEs accounted for $99.52 \%$ of the total establishments in the Philippines and employed $62.9 \%$ of their workforce in the domestic and global markets. (Department of Trade and Industry, 2020). In the small island province of Marinduque, which is the setting of this study, the majority of the enterprises is categorized as micro and small-sized only.

Having accounted that about ninety-nine percent of the establishments in the Philippines is comprised of MSMEs, it can be deduced that they can significantly contribute to the country's economic growth. But in 2017, the World Development Indicators of World Bank disclosed that the GDP growth of the Philippines (5.6\%) was lower as compared to other Southeast Asian neighbors

Corresponding author

Michael V. Capiña, mvc11477@gmail.com

DOI: (to be assigned soon)

Research Synergy Foundation 
Journal of Social Entrepreneurship Theory and Practice (JSETP), Vol. 1 (1), 84-97

Impact of Management Practices on Micro and Small Enterprise (MSEs) Performance in Marinduque,

Philippines

Michael V. Capiña

like Bangladesh (6.2\%), Vietnam (6.6\%), Cambodia (6.6\%), and Myanmar (8.5\%) from 2007 to 2016. Also, the Report of International Finance Corporation's Ease of Doing Business Technical Notes as cited in the 2017 Proposed National Budget showed that the Philippines' level of business competitiveness lags as compared to other ASEAN countries. From 97th place in 2015, the Philippines dropped six notches to 103rd in 2016 in the Doing Business Survey. In the Starting a Business Category, the country slipped from the 157th to 165th slot, out of 189 nations included in the survey.

Conversely, at the regional level, it was reflected in the Philippine Development Plan 20172022 that the Average Regional Share in GDP from 2010-2015 of the MIMAROPA Region was 2\%, with an average growth rate of 3\% in Gross Regional Domestic Product (GRDP) and Regional Contribution to GDP Growth of $.01 \%$. While the PSA MIMAROPA 2006-2019 Economic Performance Report further disclosed that the GRDP of about 8.6\% from year 2016 to 2017 declined to $3.9 \%$ in the period $2018-2019$, indicating a fluctuating GRDP in the region.

The essential nature of MSMEs in stimulating social progress in a developing economy, like the Philippines, is widely recognized. To support the sector, government agencies such as DOST, DTI, DOLE, and DAR, consistently provide programs and interventions. Among the most active, DOST downloads assistance to MSMEs through the programs Grant in Aid (GIA) for groups, while Small Enterprise Technology Upgrading (SETUP) is for individuals.

However, Buan reported in 2019 thru a news article that the Commission on Audit (COA) called out DOST for inefficient implementation of the SETUP program. Buan further disclosed that in the 2018 Audit Report of COA, DOST had accumulated P461.150 million uncollected refunds that have been due for up to 10 years and that the program has minimal returns to the government's investments. In addition, the study of Herpacio and Hidalgo in 2018 asserted that major problems are being encountered by the recipients during the implementation of DOST-SETUP, such as defective equipment, failure to meet the repayment schedule, and non-compliance to documentary requirements.

In Marinduque, the majority of the enterprises operating in the province falls under the micro and small-sized category. In 2016, about 69 business establishments were being assisted by DOST, mostly by providing technology upgrading assistance. Support downloaded by DOST to the MSMEs comes either from two types of programs, namely: Grant in Aid (GIA) and Small Enterprise Technology Upgrading (SETUP). Despite the assistance, according to DOST, there was five Grant in Aid and one SETUP recipient that did not continue operations while the majority of them are stagnant or low in productivity and profitability.

Marinduque is one of the provinces in the MIMAROPA Region. Notwithstanding being described as a small island in the southeastern portion of Luzon and Mindoro Islands, the heartshaped Marinduque is famous for its tourist attractions such as the Moriones Festival, which is an antiquated celebration of the Holy Week, white sand beaches, ancient caves, hidden waterfalls, scenic drives and picnic spots, Spanish churches standing and ruins of Baroque/Roman influences, a warm, friendly and hospitable people, and exotic souvenirs. These features could offer a wide array of opportunities towards the advantage of the MSMEs in the province, considering the nature of their business operations.

Considering the foregoing premises, the researcher aimed to conduct critical investigation and analysis of the MSMEs in Marinduque, specifically those assisted by DOST, in order to assess 
the impact of their management practices on operational functions (marketing, production, financial, human resources) and the significant relationship to the MSEs performance (sales, production, and income).

\section{LITERATURE REVIEW}

\section{Management Practices}

Working methods and innovations used by managers can be refferd as management practices. Those practices are expected to enhance the work system's effectivensess. There are various management practices available, such as empowering employee, training and development for quality improvement, and knowledge sharing about new technologies (IGI Global's Online Bookstore, 2019).

However, according to Forth and Bryson (2018), MSMEs rarely used formal management practices compared to larger companies. On the other hand, management practices found to be beneficial for MSMEs, as it can help to enhance their productivity. Especially training and development for MSMEs human resources, such as skill training and introducing formal performance target.

Broszeit et al. (2016) looked into the influence of formal management techniques on MSME performance, finding that they have a beneficial effect, but one that is weaker than that shown in bigger companies. The few studies that have been done have relied on subjective performance ratings provided by the same respondents who report on the firm's management procedures.

\section{Operational Business Functions}

According to ERP Gold (2017), management is the "brain" of every corporate operation. Functional management focuses on arranging and guiding an organization's talent to complete a specified organizational task within functional domains. There are five major management functional areas: Human resource management, production management, office management, financial management, and marketing management are all aspects of human resource management.

Business processes may be categorized into four main areas, according to the International Trade Centre (2014) in their book "A Guide to Diagnose a Business and Its Management." 1. 'Strategic processes' are those that deal with the initial identification of a client and a suitable offer; 2. 'Marketing processes' are those that deal with advertising, promotions, client negotiation, and other tactical marketing processes; 3. 'Production processes' are those that deal with the production and delivery of the offer; and 4.

Production and operation are at the heart of each industrial business. Any flaw in the production process results in not only delays in delivery, but also needless costs. To keep costs down and maintain a smooth flow of production activities, it's critical that manufacturing issues are detected early on and handled quickly. The following are the tools for improving operations that have been identified: 1 . Order quantity control charts, 2 . Order quantity control charts, 3. Order quantity control charts, 4. Order quantity control charts, 5. 4. Just-in-time, 5. Routing diagram, 6. Run Charts, 7. Simplified plant layout, and 8. Value analysis and value engineering (Negosyo Center Business Counselors Manual, 2016).

According to DTI's Small Business Counselors Manual 2016, the following marketing tools and tactics are designed to enhance expertise in strategies connected with the 4 Ps of marketing 
Journal of Social Entrepreneurship Theory and Practice (JSETP), Vol. 1 (1), 84-97

Impact of Management Practices on Micro and Small Enterprise (MSEs) Performance in Marinduque,

Philippines

Michael V. Capiña

and sales forecasting techniques: 1. Distribution channel diagram, 2. Five-force analysis, 3. Positioning map, 4. Pricing strategies, 5. Product life cycle strategies, 6. Product strategies, 7. Promotion strategies, 8. Sales forecasting techniques, and 9. Value chain analysis

Financial data analysis is a difficult process. To analyze the success of a corporate entity, you'll need several instruments. It's critical to hone your financial analysis abilities and be able to evaluate and communicate financial data in a clear and understandable manner. The following are some of the financial instruments: 1 . Break-even analysis, 2. Financial statement of common size, 3. Financial ratio analysis, 4. Internal rate of return, 5. Buy or sell decision 7. Payback period, 6. Net present value (Negosyo Center Business Counselors Manual, 2016).

\section{MSMEs Performance}

Because businesses are under pressure to provide effective and efficient outcomes, measuring business performance has become a critical topic in both academics and business. Due to the multi-dimensional characteristics of performance, there is no one overarching model for measuring the success of small businesses. Depending on the firm's goals, performance may be measured using a variety of techniques. Most researchers suggest hybrid measures of performance (financial and non-financial measurements) to integrate its multi-dimensional character and to overcome the problems of a single measure of performance (Gerba et al., 2016). In order to assess the success of SMEs, Liridon (2017) utilized the following indicators: growth, profitability, productivity, and sales.

Alaskari (2014) established a technique for evaluating the performance of small and medium-sized companies (SMEs) in the manufacturing sector using qualitative and quantitative metrics that can quantify the potential and advantages available to SMEs. The evaluation approach was effective in discovering hidden possibilities and advantages, establishing world-class performance of the firms, and comparing this to existing performance to identify gaps in performance, according to the results.

The use of performance measurement models guarantees alignment with a company plan, implying that the performance indicators used are organization-specific. There is typically a dearth of advice in such measurement models on the performance indicators that exist and how they may be concretized in reality. A structured literature study was undertaken to discover patterns or trends in the research on business process performance assessment in order to address this gap. To get a holistic view, the study compiled a list of 140 process-related performance indicators and classified them into 11 performance perspectives (Van Looy and Shafagatova, 2016).

Internal and external variables impacting MSMEs' success were highlighted by Sitharam and Hoque (2016). The internal environment includes a variety of elements such as technical capabilities, management competence and skills, and financial availability. While regulatory issues are important, MSMEs also face substantial difficulties from macroeconomic variables, competitiveness, globalization, and crime and corruption. The business's performance would be enhanced by technological progress. Among the internal and external elements investigated, competition was the only one that showed a significant relationship with MSMEs' success.

Traditional company performance management centered solely on financial performance must be complemented and addressed with strategic business performance management 
methodologies and models. Managerial Information Systems (MIS) and Controlling have a substantial influence on improving corporate performance (Zamecnik and Rajnoha, 2015).

In a study titled "The Performance of Micro, Small, and Medium Enterprises (MSMEs): Indigenous Ethnic Versus Non-Indigenous Ethnic," Hamzani et al. (2016) stated that MSMEs' performance could be measured by the following indicators: increased profits; financial condition; ability of MSMEs products to compete; increase customer; increase in sales volume; employee satisfaction; employee satisfaction; employee satisfaction; employee satisfaction; employee satisfaction; employee satisfaction; employee satisfaction; employee satisfaction; employee satisfaction; employee satisfaction (Ardiana and Subaedi, 2010). Meanwhile, increasing production, the expansion of business units, the increase in sales volume, and higher revenue (income) are all indications of performance, according to Rante (2010).

\section{RESEARCH METHOD}

This study utilized descriptive and quantitative research. The research study was conducted in the province of Marinduque covering the six municipalities namely: Boac, Mogpog, Santa Cruz, Torrijos, Buenavista, and Gasan.

The sample of the study was based on the Department of Science and Technology (DOST) Marinduque Assisted Projects as of 2016 who involved in manufacturing business establishments, and the study was conducted in the year 2018. Purposive sampling was used in the selection of respondents. Participants in this study were selected based on the following criteria: a) Business establishments registered in the 6 municipalities of Marinduque and are categorized as MSME; b) Established operation for about 3 years; c) Recipient of DOST GIA and SETUP project for about 3 years; and d) Involved in Manufacturing. After evaluation, only 35 MSEs qualified, with 105 respondents consist of the owner, manager, and employee who answered the survey questionnaire.

To obtain reliable and valid information, the researcher used a self-made survey questionnaire and guide questions validated by experts. A pilot study was carried out to test the reliability of the research instrument. The questionnaire was tested for internal consistency reliability using Cronbach's coefficient alpha determined using SPSS with an alpha value of 0.980 indicates excellent consistency, and the majority of the factor analysis for all the parameters for each of the variables results in 1 component. Inferential statistics were used to facilitate interpretation of the management practices on operational functions (marketing, production, financial, human resources) and analysis of the significant relationship to MSEs performance (sales, production, and income) using Pearson Correlation.

\section{FINDINGS AND DISCUSSION}

\section{Profile of the Participants}

Out of the 35 selected manufacturing MSMEs, 13 or $42 \%$ are GIA, and 18 or $58 \%$ are SETUP. Four of the identified SETUP did not respond due to health issues and emergency cases during the conduct of the study. There are 74 out of 105 , or $70.47 \%$ of the target respondent participated in the study, as shown in Table 1.

Table 1. Number of Respondents Participated

\begin{tabular}{|l|l|l|l|l|}
\hline Respondents & GIA & SETUP & Total & Percentage \\
\hline
\end{tabular}


Journal of Social Entrepreneurship Theory and Practice (JSETP), Vol. 1 (1), 84-97

Impact of Management Practices on Micro and Small Enterprise (MSEs) Performance in Marinduque, Philippines

Michael V. Capiña

\begin{tabular}{|l|c|c|c|c|}
\hline Officers/Board of Directors & 12 & & 12 & $16.22 \%$ \\
\hline Owner & & 18 & 18 & $24.32 \%$ \\
\hline Manager & 10 & 10 & 20 & $27.03 \%$ \\
\hline Employee Total & 11 & 13 & 24 & $32.43 \%$ \\
\hline \multicolumn{2}{|c|}{$\mathbf{4 1}$} & $\mathbf{7 4}$ & $\mathbf{1 0 0 . 0 0 \%}$ \\
\hline
\end{tabular}

While Table 2, Figure 1, and Figure 2 show the profile of the participant MSMEs of the study.

Table 2. Years of business operation

\begin{tabular}{ccccc}
\hline & GIA & SETUP & Total & Percentage \\
\hline $\mathbf{3}$ to $\mathbf{5}$ & 25 & 2 & 27 & $36.49 \%$ \\
$\mathbf{6}$ to10 & 8 & 8 & 16 & $21.62 \%$ \\
$\mathbf{1 0}$ above & & 31 & 31 & $41.89 \%$ \\
Total & $\mathbf{3 3}$ & $\mathbf{4 1}$ & $\mathbf{7 4}$ & $\mathbf{1 0 0 \%}$ \\
\hline
\end{tabular}

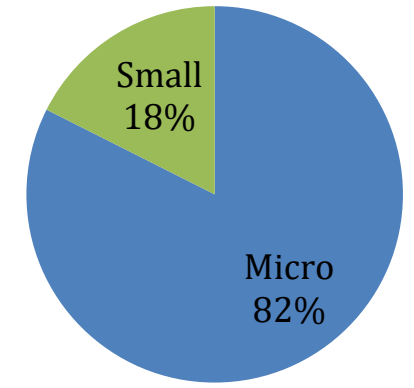

Number of Employee

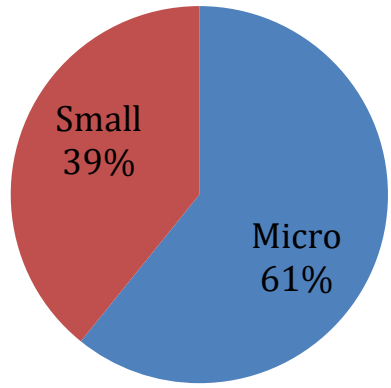

Assets

Figure 1. Category of MSMEs as to number of employees and assets

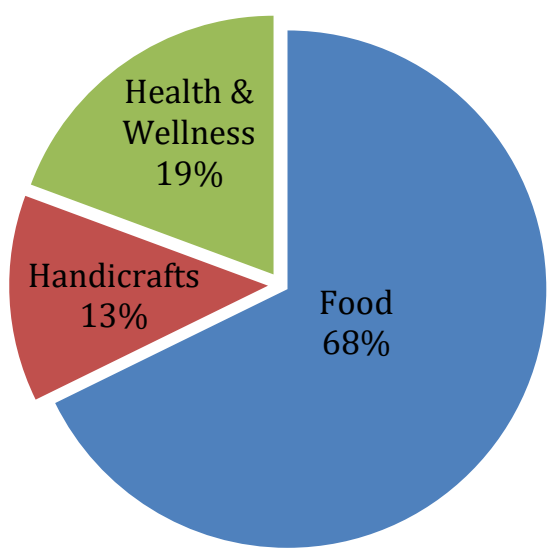

Figure 2. Types of products manufactured by MSMEs

\section{Management practices on operational business function}


Journal of Social Entrepreneurship Theory and Practice (JSETP), Vol. 1 (1), 84-97

Impact of Management Practices on Micro and Small Enterprise (MSEs) Performance in Marinduque,

Philippines

Michael V. Capiña

An operational business function is the functional areas of business operations as to marketing, production, financial, and human resource management aspect. According to businessdictionary.com, "Functional Areas" is defined as the grouping of activities or processes on the basis of their need in accomplishing one or more tasks. It's also an alternative term for a business unit. These are the most common areas of operation that MSEs are involved.

Table 3. Management practices on operational business function

\begin{tabular}{lcc}
\hline \multicolumn{1}{c}{ Operational Functions } & Mean & Verbal Description \\
\hline Marketing & 3.95 & Mostly Practiced \\
Production & 3.94 & Mostly Practiced \\
Financial & 3.50 & Mostly Practiced \\
Human Resources & 3.40 & Practiced \\
Overall Mean & $\mathbf{3 . 7 0}$ & Mostly Practiced \\
\hline
\end{tabular}

Table 3 discloses the management practices on operational business function. As shown, respondents believe that the MSEs are doing well in relation to operational business function. The overall mean is 3.70, which is interpreted as "Mostly Practiced". This implies that the respondents highly regard the efforts being exerted by the organizations involved. Of all the variables, marketing emerged to have garnered the highest mean of 3.95, which is interpreted as "Mostly Practiced". This finding is a dead give-away simply because all businesses presented are all profit organizations.; thus, marketing is expected to be on top of the list.

What is alarming in the aforementioned data is human resources which got the lowest mean of 3.40, interpreted as "Practiced". This finding somehow contradicts the fact that businesses that value their employees tend to perform better than those that don't. It is a fact also that happy and satisfied employees are more productive, which, in turn, helps improve their overall quality of work. According to Katyal and Xaviour (2015), as MSMEs focus more on running the business on a day-to-day basis, they find less time to manage the Human Resource processes, which is perceived as non-priority. MSMEs do not feel like revamping existing organizational structure, especially when they know that the status quo is delivering the output. The competitiveness of MSME can be enhanced through better human resource (HR) practices of recruitment, selection, training and compensation.

Operational business function in relation to marketing focuses on four Ps such as product, price, place of distribution, and promotion. Table 2 discloses the data on marketing management practices. As revealed, the overall mean is 3.95, which is interpreted as "Mostly Practiced". This means that the respondents have witnessed high dedication among the players to practice and demonstrates the above-mentioned practices.

Table 4. Marketing Management Practices

\begin{tabular}{lcc}
\hline \multicolumn{1}{c}{ Marketing } & Mean & Verbal Description \\
\hline Product & 4.10 & Mostly Practiced \\
Price & 4.08 & Mostly Practiced \\
Place of distribution & 3.85 & Mostly Practiced \\
Promotion & 3.77 & Mostly Practiced \\
\hline Overall Mean & $\mathbf{3 . 9 5}$ & Mostly Practiced \\
\hline
\end{tabular}


Journal of Social Entrepreneurship Theory and Practice (JSETP), Vol. 1 (1), 84-97

Impact of Management Practices on Micro and Small Enterprise (MSEs) Performance in Marinduque,

Philippines

Michael V. Capiña

As shown, of all variables, the "Product" got the highest mean of 4.10, which is interpreted as "Mostly Practiced". According to Mayuri (n.d), pricing decisions can have very significant consequences for the organization because it's one of the customers' considerations in buying the product; thus, it also determines the profit margin. It also determines the future of the product, acceptability of the product to the customers and return and profitability from the product. In short, it's a tool of competition.

In the meantime, "Promotion" got the lowest mean of 3.77, which means that of all variables, it's practiced but last in the list of marketing management. Specifically, this was the most critical and important part of the MSEs activities because generating sales and income depend on it. Market distribution and ways of reaching the customer through promotions and positioning on the minds of the consumer play a vital role.

The production aspect of the business enterprise was among the most complicated and significantly influenced the success of a chosen venture. Developing products suited and demanded by the market or the consumers expect better products. The focus of production will be on the production process, raw materials \& supplies, facilities \& equipment, and purchasing \& inventory.

Table 5. Production Management Practices

\begin{tabular}{lcc}
\hline \multicolumn{1}{c}{ Production } & Mean & Verbal Description \\
\hline Production Process & 3.85 & Mostly Practiced \\
Raw Materials \& Supplies & 3.96 & Mostly Practiced \\
Facilities \& Equipment & 3.95 & Mostly Practiced \\
Purchasing \& Inventory & 4.02 & Mostly Practiced \\
\hline Overall Mean & $\mathbf{3 . 9 4}$ & Mostly Practiced \\
\hline
\end{tabular}

Table 5 features the survey results on production management practices. It can be seen that the overall mean is 3.94 , which is interpreted as "Mostly Practiced". All variables got means interpreted as "mostly practiced" except "production process", which got the lowest mean of 3.85. With the fierce competition in the market, a good production process and quality control system becomes an important factor that differentiates one from the other. Maintaining a good quality of products acceptable in the market involves several processes and technical expertise. As of this date, they are in the process of complying and passing other mandatory requirements for accreditation by BFD and FDA.

Table 6 shows the results of the survey as to financial management practices. As shown, the overall mean is 3.50, which is interpreted as "Mostly Practiced", affirming the fact that finance is the "life blood" of the enterprise, and their success is measured thru financial indicators like Financial Statement or FS. But the study used the following financial aspect: record keeping \& management, profitability, liquidity, and leverage.

Table 6. Financial Management Practices

\begin{tabular}{lcc}
\hline \multicolumn{1}{c}{ Financial } & Mean & Verbal Description \\
\hline Record Keeping \& Management & 3.81 & Mostly Practiced \\
Profitability & 3.64 & Mostly Practiced \\
Liquidity & 3.39 & Practiced \\
Leverage & 3.15 & Practiced \\
\hline Overall Mean & $\mathbf{3 . 5 0}$ & Mostly Practiced \\
\hline
\end{tabular}


Journal of Social Entrepreneurship Theory and Practice (JSETP), Vol. 1 (1), 84-97

Impact of Management Practices on Micro and Small Enterprise (MSEs) Performance in Marinduque,

Philippines

Michael V. Capiña

Leverage got the lowest mean of 3.15, which is interpreted as "Practiced", which means that most probably are afraid of long-term obligation. This is because the government's support is very lively, and most of the time, they are the beneficiary of the grant or fund transfer from the government without an obligation of paying but to improve and sustain the business operation.

Human resource is considered as among the most important assets of the MSEs; that is why proper management and supervision matters in the performance and success of a business enterprise. Area's for human resources are the following: hiring \& firing, incentives \& benefits, performance evaluation, and training \& development.

Table 7. Human Resource Management Practices

\begin{tabular}{lcc}
\hline \multicolumn{1}{c}{ Human Resources } & Mean & Verbal Description \\
\hline Hiring \& Firing & 3.47 & Practiced \\
Incentives \& Benefits & 3.53 & Mostly Practiced \\
Performance Evaluation & 3.18 & Practiced \\
Training \& Development & 3.43 & Practiced \\
\hline Overall Mean & $\mathbf{3 . 4 0}$ & Practiced \\
\hline
\end{tabular}

Table 7 discloses the results of the survey as to human resource management practice. As revealed, the overall mean is 3.40 , which is interpreted as "Practiced". The result of the study shows that this aspect is one of the non-priority of the DOST assisted projects. Performance evaluation has the lowest mean of 3.18 followed by training and development with 3.43. The employee's performance and evaluation most of the time is based only on the perception and trust of the owner and manager. Most of them slightly practiced performance evaluation in a formal way.

MSMEs are less likely to use formal management practices than larger firms, but that such practices have demonstrable benefits for those who use them, helping firms to grow and increase their productivity. The returns are most apparent for those SMEs that invest in human resource management practices, such as training and performance-related pay and those that set formal performance targets (Forth \& Bryson, 2018). Managing people are among the challenging role of a manager. As the business enterprise grows, the need for the right people also increases. Thus, selecting the right people and evaluating performance should be part of the package but sad to say, this is sometimes overlooked by most of the MSEs.

\section{MSEs Performance}

At the end of every business cycle or calendar, an evaluation of performance and accomplishment of targets measures how wealthy and healthy the business enterprise operator is. Performance can be evaluated thru the use of financial analysis as a tool. However, the research study used only the non-financial data and interviews with co-participants. MSEs performance focused on the following: sales, production, and income.

Table 8. MSEs Performance

\begin{tabular}{lcc}
\hline \multicolumn{1}{c}{ MSEs Performance } & Mean & Verbal Description \\
\hline Sales & 3.65 & Very Satisfactory \\
Production & 3.70 & Very Satisfactory \\
Income & 3.57 & Very Satisfactory \\
\hline Overall Mean & $\mathbf{3 . 6 4}$ & Very Satisfactory \\
\hline
\end{tabular}


Journal of Social Entrepreneurship Theory and Practice (JSETP), Vol. 1 (1), 84-97

Impact of Management Practices on Micro and Small Enterprise (MSEs) Performance in Marinduque,

Philippines

Michael V. Capiña

Table 8 shows the overall performance of MSEs. As shown, the overall mean for this table is 3.64 , which is interpreted as "very satisfactory". All the variables are interrelated to each other, which was manifested in the mean result. Although very satisfactory, still there is a need for improvement to compete in the ASEAN market as the onset of ASEAN integration.

As to sales peak season is during the month of November to May, and the lean season is from June to October. All Saint's Day and All Soul's Day are celebrated in the month of November. Most of Marindqueno's and other Balik- Bayan visit the province to see the remains of their loved ones or relatives. This is the kick-off of the flock of tourists in the province until summer to celebrate the Holy Week and witness the Moriones Festival, wherein the province knows to be the Lenten Capital of the Philippines.

Presents the performance in terms of production resulting in an overall mean of 3.70 , interpreted as "very satisfactory". Most of them see that utilizing waste can improve production. This needs to be considered in utilizing waste and improving the production process and use of technology. Experts agree that minimizing waste in production is important because it helps protect the environment, makes good business sense, saves money through avoided disposal and raw materials purchase costs, reduces regulatory burdens and compliance costs, builds better community relations, minimizes short and long term liability, creates safer working conditions for employees, protects human health and the environment, demonstrates environmental leadership, and improves competitiveness through greater deficiencies and decreased overhead costs.

MSEs performance on income got the lowest overall mean of 3.57, which is interpreted as "very satisfactory". An indicator that problem on working capital results in low production and income. As a result of the interview, there is a need to manage receivables in order not to escalate and to avoid bad debts. Not all were performing well; some of them were struggling for better sales and a sustainable market. Marginal production due to low working capital and sluggish market distribution hamper their profitability. Most of their raw materials are indigenous to the province, like arrowroot, buntal, and abaca, which cannot serve and sustain large volumes of orders. Majority of single proprietorship and family business enterprise is doing well and is able to sustain operations and gain substantial profit as compared to a group like cooperatives and associations or community-based enterprises. Increasing and competing outside the province is a good opportunity but needs additional capital and improved facilities.

\section{Relationship of management practices on operational functions to MSEs Performance}

Using Pearson Correlation with .857 and a P-value of 0.000 reveals that management practices on business operational function have a significant relationship on performance. Since Pvalue is less than the 0.05 level of significance, there is a positive correlation between operational function on the performance of the MSEs.

According to Neneh and Van Zyl (2012), all six selected business practices that were examined (marketing practices, strategic planning practices, human resource management practices, risk management practices, performance management practices and teamwork practices) have a positive and significant relationship with SME performance. Moreover, $97.1 \%$ of the SMEs that implemented all six business practices had an optimal business performance.

Broszeit et al. (2016) explicitly investigate the impact of formal management practices on SME performance, finding that such practices have a positive effect, but one that is weaker than that 
found among larger firms. Those studies which do exist have used subjective ratings of performance provided by the same respondents who reported on the firm's use of management practices. Wu et al. (2015), Lai et al. (2015) and Sheehan (2014) all find positive associations between the use of formal management practices and performance among SMEs (Forth and Bryson, 2018).

Meanwhile, Motlhaudi (2014) identifies dominant business practices that South African SMEs engage in, namely: HRM practices, Performance Management practices, Change Management practices, Risk Management practices, Marketing practices and Networking practices. These business practices proved to play a significant role in the positive performance of SMEs; however, they did not address the staggering failure rates of SMEs.

\section{CONCLUSION}

Based on the foregoing analyses of the findings, the researcher came up with the following conclusions:

1. Almost $40 \%$ of the respondents belong to the small enterprise category with $\mathrm{PhP} 3$ million to $\mathrm{PhP} 15$ million assets, and 10-99 employees thus are considered the top performers, economically healthy and have the potential to capture market opportunities outside the province.

2. Marketing is the most critical and important part of the MSEs activities because generating sales and income depends on it. Nevertheless, as to their experiences and observation, price competitiveness is affected by distance or location. Because the province is an island, the cost of transportation added extra expenses from getting materials and selling products outside the province.

3. Production is an important or essential facet of management that deals with decisionmaking regarding the quality, quantity, cost, etc., of production. As reiterated, the main objective of production management is to produce goods and services of the right quality, right quantity, at the right time and at minimum cost. Product improvements and innovations are among the strategies that need further consideration in order to compete in the local and even international market.

4. Marginal production due to low working capital and sluggish market distribution hamper their profitability. Majority of single proprietorship and family business enterprise is doing well and is able to sustain operations and gain substantial profit while cooperatives and associations are struggling for better sales and sustaining day to day operations.

5. Effective record keeping regularly monitors the overall growth of the business, assists in strategizing business policies, determines income sources, and fosters higher work efficiency. Recording and maintaining records and maximizing the responsibilities of the treasurer should be monitored and properly audited in cooperatives or associations. Occasionally trust is not enough to protect the fund of the company or enterprise.

6. Human resources are considered as among the most important assets of the MSEs; that's why proper management and supervision matter in the performance and success of a business enterprise. They are one of the non-priority parts and need further attention on performance evaluation and training and development. 
Journal of Social Entrepreneurship Theory and Practice (JSETP), Vol. 1 (1), 84-97

Impact of Management Practices on Micro and Small Enterprise (MSEs) Performance in Marinduque, Philippines

Michael V. Capiña

7. Type of DOST assistance has a significant part on the operational business functions and performance but should consider the capability of owner/manager, knowledge, and type of business organization for giving intervention.

8. Based on the operational management experiences of SETUP and GIA, the following have a vital role for the success of MSEs such as type of business organization, decision-making process, creation of policy, rules, and regulations, planning and implementation, and management directions of the enterprise.

9. In a nutshell, both small and large business companies need the assistance of human resources to survive and succeed. In fact, it's common knowledge that it's crucial for the success of any business. Further, they are the company's biggest asset not only on daily operations but on the competitive advantage. In today's business demands, having good and effective human resources makes the business more productive and profitable. Thus, they need to be managed properly not only for increased productivity and reduced costs but also to ensure high morale and trust among your workforce.

The proponent would like to recommend the following:

1. Assistance from the government agencies for grant or transfer of funds to (Grant in Aid) GIA should give emphasis on the obligations and responsibilities of the beneficiary.

2. Creation of a Management team for organizations and cooperatives should be autonomous in terms of the business operation to empower and hasten the decision-making process. Also, to have permanent human resources to focus on enterprise management and sustainability.

3. Competitiveness of MSME should be enhanced through better Human Resource (HR) practices of recruitment, selection, training and compensation.

4. Preparation for expanding and sustaining a bigger market share should be taken into consideration and be a part of the long-term plans.

5. Government intervention for the MSEs should be tailored based on the capability of the owner/manager and the current condition of the enterprise, including the owner or managers' attitude and character.

6. Researcher/s can further the research topic by developing a regression model that possibly is able to test the level of importance and in-depth relationships of the operational business function to MSMEs' performance in Marinduque.

\section{REFERENCES}

Broszeit, S. \& Laible, M. C. (2016). "German management and organizational practices survey (GMOP 0813): Data collection," FDZ Methodenreport 201606_en, Institut für Arbeitsmarkt- und Berufsforschung (IAB), Nürnberg [Institute for Employment Research, Nuremberg, Germany].

Buan Lian, (2019). DOST's Program for Small Business Called Out for Wasting Millions. https://www.rappler.com/nation/235999-dost-program-small-businesses-audit-report-2018

Business Dictionary (2018, November). WebFinance Inc. Retrieved November 2018, from business dictionary: http://www.businessdictionary.com/definition/diagnosis.html 
Department of Trade and Industry. (2020). 2018 MSME Statistics. https://www.dti.gov.ph/business/msmes/msme-resources/msme-statistics

Department of Trade and Industry and University of the Philippines Institute for Small Scale Industries. (2016). Small Business Counselors Course Manual. Manila: Department of Trade and Industry.

Forth J. \& Bryson, A. (2018). The Impact of Management Practices on SME Performance. Bonn, Germany: IZA - Institute of Labor Economics.

Gerba Yirgalem Tadele, V. P. (2016). Performance measurement of small scale enterprises: Review of theoretical and empirical literature. International Journal of Applied Research, 531-535.

Gold, E. (2017, January 27). ERP Gold. Retrieved November 9, 2017, from https://www.erp.gold/5-important-functional-areas-management

Hamzani Umiaty \& Achmad Dinarjad (2016). The Performance of Micro, Small and Medium Enterprises (MSMEs): Indigenous Ethnic Versus Non-Indigenous Ethnic. Procedia - Social and Behavioral Sciences Vol. 219, pages 265-271, ISSN 1877-0428

Herpacio, C. A., \& Hidalgo, H. .. (2018). Impact Assessment of State Assistance Program to Agri-based Micro, Small and Medium Enterprises in the Philippines. International Journal on Advanced Science Engineering Information Technology , 2547-2554.

IGI Global's Online Bookstore, (2019). Management Practices. https://www.igiglobal.com/dictionary/multi-agent-simulation-management-practices/17783

International Trade Centre (ITC). (2014). A Guide to Diagnose a Business and its Management. Geneva: ITC Digital Printing Service.

Katyal A. \& Xaviour B. (2015). A Study on MSMEs'- Role in Propelling Economic Development of India \& a Discussion on current HR issues in MSMEs' in India. International Journal of Scientific and Research Publications, Volume 5, Issue 2, February 2015

Knowledge Management and Fiscal Transparency Service (2016). Technical Notes on the 2017 Proposed National Budget . Manila: Department of Budget and Management.

Liridon Veliu, M. M. (2017). The Impact of Managerial Competencies On Business Performance: SME's In Kosovo. Vadyba Journal of Management, 59-65.

Mohammad Munir Ahmad Osama Alaska , (2014), "Development of assessment methodology for improving performance in SME's", International Journal of Productivity and Performance Management, Vol. 63 Iss 4 pp. 477 - 498

Motlhaudi, G. G. (2014). Business Practices As An Implication For SMEs Growth. Bloemfontein, South Africa: University of the Free State.

National Economic and Development Authority (2017). Philippine Development Plan 20172022. Manila, Philippine: National Economic and Development Authority.

N.B. Neneh \& J.H. van Zyl (2012). Achieving Optimal Business Performance Through Business Practices: Evidence from SMEs in Selected Areas in South Africa. Southern African Business Review Volume 16 Number 3, 118-144.

Sitharam, Sharmilee \& Hoque, Muhammad. (2016). Factors affecting the performance of small and medium enterprises in KwaZulu-Natal, South Africa. Problems and Perspectives in Management. 14. 277-288 and 258. 10.21511/ppm.14(2-2).2016.03. 
Journal of Social Entrepreneurship Theory and Practice (JSETP), Vol. 1 (1), 84-97

Impact of Management Practices on Micro and Small Enterprise (MSEs) Performance in Marinduque,

\section{Philippines}

Michael V. Capiña

Van Looy, Amy \& Shafagatova, Aygun. (2016). Business process performance measurement: a structured literature review of indicators, measures and metrics. SpringerPlus. 5. 10.1186/s40064-016-3498-1.

World Development Indicators of World Bank (2017).

Zamecnik, Roman \& Rajnoha, Rastislav. (2015). Strategic Business Performance Management on the Base of Controlling and Managerial Information Support. Procedia Economics and Finance. 26. 769-776. 10.1016/S2212-5671(15)00843-6. 